\title{
Effects of Xylooligosaccharides in Type 2 Diabetes Mellitus
}

\author{
Wayne Huey-Herng SHEU ${ }^{1-4}$, I-Te LEE ${ }^{1,2}$, Wei CHEN $^{5}$ and Yin-Ching CHAN ${ }^{5, *}$ \\ ${ }^{1}$ Division of Endocrinology and Metabolism, Department of Internal Medicine, Taichung Veterans \\ General Hospital, Taichung, Taiwan \\ ${ }^{2}$ Institute of Medicine, Chung Shan Medical University, Taichung, Taiwan \\ ${ }^{3}$ Institute of Medical Technology, National Chung-Hsing University, Taichung, Taiwan \\ ${ }^{4}$ School of Medicine, National Yang-Ming University, Taipei, Taiwan \\ ${ }^{5}$ Department of Food and Nutrition, Providence University, \\ 200 Chungchi Rd., Shalu, Taichung 433, Taiwan
}

(Received April 22, 2008)

\begin{abstract}
Summary The purpose of this study was to evaluate the effect of xylooligosaccharide (XOS) on the blood sugar, lipids and oxidative status in type 2 diabetes mellitus (DM). A total of 26 outpatient subjects of Taichung Veterans General Hospital, Taiwan, with HbA1c levels between 7.0 and $10.0 \%$ and triglyceride $<400 \mathrm{mg} / \mathrm{dL}$ were enrolled in the present study. Subjects were supplemented with $4 \mathrm{~g} / \mathrm{d}$ XOS $(n=12)$ or a placebo $(n=14)$ for 8 wk in a randomized double-blind clinical design. The results showed that the anthropometric values and nutrient intakes did not change during the experimental period. XOS supplementation not only reduced the glucose, $\mathrm{HbAlc}$ and fructosamine concentrations, but also decreased the levels of total cholesterol, low density lipoprotein (LDL) cholesterol, oxidized low density lipoprotein (ox-LDL) and apolipoprotein B. The activity of catalase of the erythrocyte sample decreased in the XOS group, but not the activities of superoxide dismutase and glutathione peroxidase. In conclusion, the dietary supplementation with XOS for 8 wk was effective in improving the blood sugar and lipids in type 2 diabetes, indicating that XOS-containing diets might be beneficial to DM subjects.
\end{abstract}

Key Words xylooligosaccharide, sugar, lipids, type 2 diabetes, antioxidant status

Dietary non-digestible oligosaccharides have gained increasing attention because they showed beneficial effects for maintaining optimum health. Xylooligosaccharides (XOS) are composed of $\beta$-1,4-linked D-xylopyranose residues. It has been demonstrated that XOS can be extensively utilized by several species of Bifidobacteria in the colon and can stimulate the growth of Bifidobacteria $(1,2)$. Hsu et al. (3) reported that XOS significantly lowered the serum triacylglycerol (TG) level and increased the Bifidobacteria population in SpragueDawley rats. Campbell et al. (4) suggested that XOS showed some beneficial effects for improving gastrointestinal health by increasing the Bifidobacteria population and providing short-chain fatty acid (SCFA). SCFAs, such as acetate, propionate and butyrate, were produced by microbial fermentation and absorbed readily by the colonic mucosa. Propionate might mediate the hepatic carbohydrate metabolism, and improve the glucose tolerance and insulin sensitivity in healthy female volunteers (5). Laurent et al. (6) found that acetate and propionate decreased the plasma free fatty acid level, while they did not change the hepatic glucose production or fasting blood glucose.

The aim of diet therapy in type 2 diabetes mellitus (DM) is not only to decrease body weight, but also to exert specific actions toward the main pathophysiologic

*To whom correspondence should be addressed.

E-mail: ycchan@pu.edu.tw disorders, such as hyperglycemia, hyperlipidemia and insulin resistance. Daily intake of $8 \mathrm{~g}$ fructooligosaccharide (FOS) for $14 \mathrm{~d}$ was reported to significantly reduce fasting blood glucose, total cholesterol and low density lipoprotein (LDL) cholesterol levels of diabetic subjects (7). On the other hand, Alles et al. (8) concluded that $15 \mathrm{~g} / \mathrm{d}$ FOS supplementation for $20 \mathrm{~d}$ did not affect the blood sugar, serum lipids or serum acetate in patients with type 2 diabetes. However, the effects of XOS on type 2 diabetes are not well documented. Therefore, the purpose of this study was to investigate the effect of XOS on blood glucose, serum lipids and serum SCFA in patients with type 2 DM. The antioxidant status of the subjects was also evaluated.

\section{MATERIALS AND METHODS}

Patients and experimental design. Twenty-six (19 men, 7 women) type 2 diabetes outpatients at Taichung Veterans General Hospital, Taiwan, were recruited in this study. This study was conducted using a doubleblinded, placebo-controlled design. All the subjects underwent physical examinations and blood tests (including liver and kidney functions). The patients were free of kidney disease, heart disease or infectious illness, gastrointestinal disease, over obesity (body mass index (BMI) >30) insulin and lipid metabolic medicine treatment, and were not smokers or antioxidant supplement users. Their glycosylated hemoglobin (HbA1c) levels were in the range of $7.0-10.0 \%$ and the TG levels 
were lower than $400 \mathrm{mg} / \mathrm{dL}$. The subjects were instructed to maintain their oral blood glucose-lowering medication, habitual eating, drinking, and lifestyle behavior. The purposes and procedures of this study were explained to the subjects, and written consents were obtained from them. Only one subject in the XOS group was under diet therapy, while other subjects were taking oral hypoglycemic agents and no patient had started drug treatment just before the study.

Participants were randomly assigned to either the supplementation with $4 \mathrm{~g} / \mathrm{d}$ xylooligosaccharides (XOS) (Xylooligo 95P, Suntory Co., Ltd., Osaka, Japan) $(n=14)$, or with the placebo $(4 \mathrm{~g} / \mathrm{d}$ glucose $)(n=12)$ for $8 \mathrm{wk}$. The daily dose was supplied in the form of powder packed in paper bags, and patients were asked to return the paper bags to assess their compliance. Patients consumed the supplements in a split dose, half of the supplement at breakfast and the other half at dinner. Sample collections and measurements were conducted at baseline (week 0) and week 8; the change of each parameter for each subject was calculated. The Human Research Ethics Committee at Taichung Veterans General Hospital and Providence University, Taichung, Taiwan, approved the study protocol.

Characteristics and nutritional assessments. A trained dietitian conducted person-to-person interviews to assess the characteristics of tested subjects, including age, gender, body composition, nutritional measurements and gastrointestinal (GI) symptoms. Anthropometric data including height, body weight and body fat were measured. Dietary intakes were evaluated by the dietitian using the 3-d food recall method, and the nutrient compositions were calculated according to the food composition table (9). Eight specific symptoms of GI were assessed using the questionnaire described by van Munster et al. (10). The listed symptoms were: appetite, rumbling numbers and sound of GI tract, belching, flatulence, fecal smell, toilet habits, stool consistency and stool traits, while the degrees of GI discomfort were ranked from absent, mild, or moderate to severe (10). Fasting venous blood of the subjects was withdrawn at baseline and week 8 by medical assistants. Part of the blood samples were centrifuged at $1,200 \times g$ for $10 \mathrm{~min}$ (Hettich Universal $16 \mathrm{R}$, Germany) to obtain serum samples for analyzing the levels of insulin, fructosamine, TG, total and high density lipoprotein (HDL) cholesterols, apolipoprotein A-I, apolipoprotein B, glutamate oxaloacetate transaminase (GOT), glutamate pyruvate transaminase (GPT), blood urine nitrogen (BUN), creatinine, and SCFA. The biochemical values were analyzed using an automatic analyzer (Synchron CX-7 systems, Beckman, USA). LDL-cholesterol was calculated according to the method of Friedewald et al. (11). The oxidized low density lipoprotein (ox-LDL) level was determined by the immuno-enzymatic method with Mercodia Oxidized LDL ELISA kits using an Elisa reader (Thermo Labsystems, USA). The fructosamine was determined by spectrophotometry (Ultrospec 1100 pro, Amersham Biosciences, USA) using a commercial test kit (Sigma Chemical Co., St.
Louis, USA). Furthermore, part of the blood sample was immediately placed in a heparinized tube and centrifuged at $4^{\circ} \mathrm{C}, 1,200 \times g$ for $10 \mathrm{~min}$ to obtain plasma and erythrocyte for the analyses of glucose and $\mathrm{HbA1c}$ levels, as well as the antioxidant status.

Analyses of oxidative status. The thiobarbituric acidreactive substance (TBARS) concentration in the plasma sample and the activities of superoxide dismutase (SOD), catalase (CAT) and glutathione peroxidase (GSH-Px) of the erythrocyte sample were determined to evaluate the oxidative status of the subjects. The concentrations of TBARS were determined according to the method described by Ohkawa et al. (12). A mixture was obtained by mixing the supernatants with $2^{\prime}$-thiobarbituric acid $(4 \mathrm{~g} / \mathrm{kg}$ in $0.2 \mathrm{~mol} \mathrm{HCl})$ and butylated hydroxytoluene $(2 \mathrm{~g} / \mathrm{kg}$ in $95 \%$ ethanol $)$ at a ratio of $1: 2: 0.3$, and then the mixture was heated at $90^{\circ} \mathrm{C}$ for $45 \mathrm{~min}$. After cooling down the mixture, $5 \mathrm{~mL}$ of $n$ butanol was added to the mixture, and then the $n$ butanol layer was separated by centrifugating at $1,000 \times g$ for $10 \mathrm{~min}$. The TBARS concentration of the $n$-butanol layer was measured spectrophometrically at $532 \mathrm{~nm}$. Experimental data were expressed as mol equivalent malondialdehyde $\mu \mathrm{M} / \mathrm{g}$ tissue, using tetramethoxypropane as the external standard and double-distilled water as the control. The SOD activity was measured using the method of Marklund and Marklund (13). A final $3.017 \mathrm{~mL}$ volume of the reaction systems contained $10 \mu \mathrm{L}$ tissue homogenates, $50 \mathrm{~mm}$ Tris- $\mathrm{HCl}$ ( $\mathrm{pH} 8.2$ ) and $50 \mathrm{~mm}$ pyrogallol. The production of formazan was determined at $325 \mathrm{~nm}$ in a spectrophotometer at $25^{\circ} \mathrm{C}$. One unit of SOD was defined as the amount of protein that inhibited the rate of pyrogallol reduction by $50 \%$. The CAT activity was measured using the method of Aebi (14). An assay mixture consisted of $1.0 \mathrm{~mL} \mathrm{H} \mathrm{O}_{2}(30 \mathrm{mM}), 2 \mathrm{~mL}$ of the supernatants of the tissue homogenates, in a final volume of $3.0 \mathrm{~mL}$. Changes in absorbance were recorded at $240 \mathrm{~nm}$ in a spectrophotometer at $25^{\circ} \mathrm{C}$. CAT activity was calculated in terms of $\mathrm{mol} \mathrm{H}_{2} \mathrm{O}_{2}$ consumed $/ \mathrm{min} / \mathrm{g}$ of tissue protein. GSH-Px activity was measured using the method of Paglia and Valentine (15). Briefly, the assay mixture consisted of $200 \mu \mathrm{L}$ of $5 \mathrm{unit} / \mathrm{mL}$ glutathione reductase (GSSG-R), $50 \mu \mathrm{L}$ of $40 \mathrm{~mm}$ glutathione (GSH), $620 \mu \mathrm{L}$ of $0.25 \mathrm{~mol}$ phosphate buffer (pH 7.4), $100 \mu \mathrm{L}$ tissue homogenates, $10 \mu \mathrm{L}$ of $20 \mathrm{~mm}$ $\beta$-nicotinamide adenine dinucleotide phosphate reduced tetrasodium salt (NADPH) and $20 \mu \mathrm{L}$ of $15 \mathrm{~mm}$ cumene hydroperoxide. The production of formazan was determined at $340 \mathrm{~nm}$ in a spectrophotometer at $25^{\circ} \mathrm{C}$. One unit of GSH-Px is defined as the amount of $\mu \mathrm{M}$ of oxidative NADPH. Data for SOD, CAT and GSH-Px activities were expressed as unit/g protein. The Pierce Micro bicinchoninic acid (BCA) protein assay was used to determine the soluble protein of samples.

Analyses of SCFA levels. Serum SCFAs, including acetate, propionate and butyrate, were determined using the method described by Murase et al. (16). An internal standard solution containing acrylic and metharylic acid with sulfosalicylic acid was prepared 
Table 1. Characteristics and anthropometric values in type 2 DM subjects supplied with placebo or XOS for 8 wk.

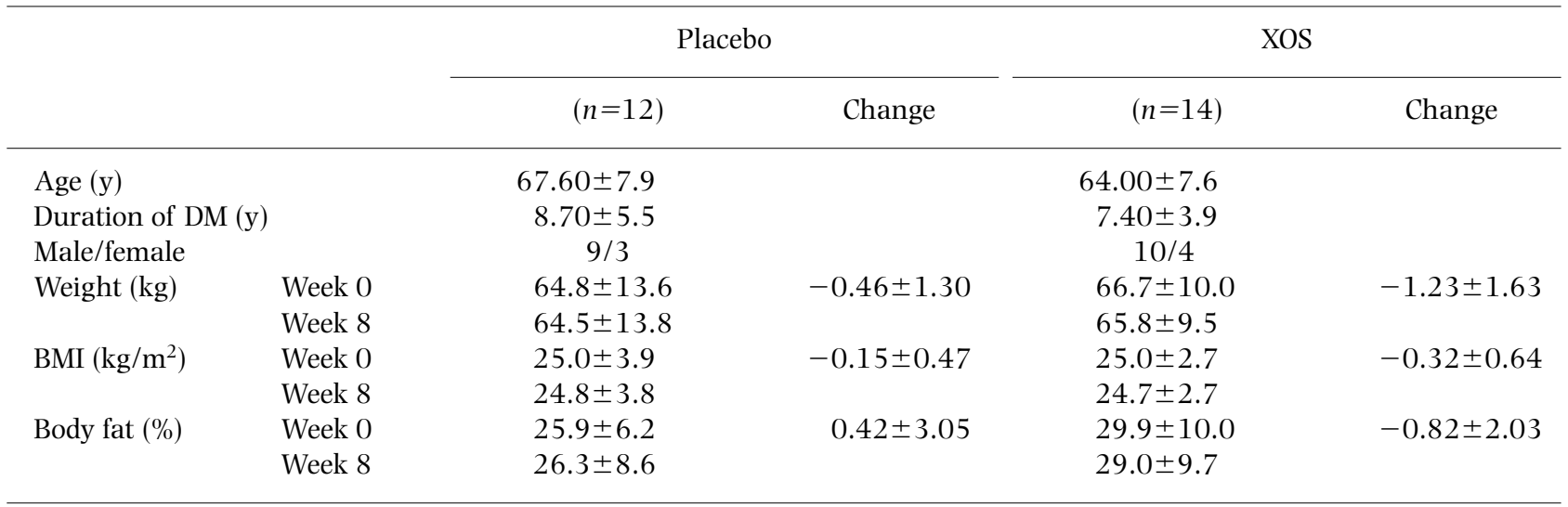

Values are expressed as mean \pm SD.

No significant difference from the baseline in the same group or between groups.

Table 2. Hematological and biochemical values in type 2 DM subjects supplied with placebo or XOS for 8 wk.

\begin{tabular}{|c|c|c|c|c|c|}
\hline & & \multicolumn{2}{|c|}{ Placebo } & \multicolumn{2}{|c|}{ XOS } \\
\hline & & $(n=12)$ & Change & $(n=14)$ & Change \\
\hline \multirow{2}{*}{ Insulin (IU/mL) } & Week 0 & $11.7 \pm 9.0$ & $0.44 \pm 5.91$ & $9.3 \pm 5.4$ & $-0.05 \pm 5.11$ \\
\hline & Week 8 & $12.1 \pm 14.4$ & & $9.2 \pm 5.8$ & \\
\hline \multirow[t]{2}{*}{ Blood glucose (mg/dL) } & Week 0 & $169.3 \pm 40.0$ & $0.17 \pm 31.69$ & $167.9 \pm 30.5$ & $-13.43 \pm 21.82^{\dagger}$ \\
\hline & Week 8 & $169.5 \pm 45.2$ & & $154.4 \pm 31.0^{\dagger}$ & \\
\hline \multirow[t]{2}{*}{ HbAlc (\% hemoglobin) } & Week 0 & $8.0 \pm 0.7$ & $0.15 \pm 0.55$ & $8.2 \pm 1.1$ & $-0.37 \pm 0.62^{\# \dagger}$ \\
\hline & Week 8 & $8.2 \pm 1.0$ & & $7.9 \pm 1.3^{\dagger}$ & \\
\hline \multirow[t]{2}{*}{ Fructosamine $(\mu \mathrm{mol} / \mathrm{L})$} & Week 0 & $422.4 \pm 92.1$ & $11.12 \pm 27.37$ & $474.6 \pm 112.6$ & $-100.32 \pm 60.66^{\# \ddagger}$ \\
\hline & Week 8 & $452.7 \pm 121.6$ & & $343.8 \pm 82.3^{\ddagger}$ & \\
\hline \multirow[t]{2}{*}{ GOT (U/L) } & Week 0 & $24.0 \pm 10.5$ & $0.09 \pm 4.25$ & $21.9 \pm 6.0$ & $4.42 \pm 11.72$ \\
\hline & Week 8 & $23.9 \pm 11.1$ & & $25.3 \pm 14.5$ & \\
\hline \multirow[t]{2}{*}{ GPT (U/L) } & Week 0 & $27.7 \pm 17.1$ & $-1.58 \pm 5.85$ & $23.6 \pm 11.0$ & $2.71 \pm 16.88$ \\
\hline & Week 8 & $26.1 \pm 14.5$ & & $26.3 \pm 18.0$ & \\
\hline \multirow{2}{*}{$\operatorname{Uric}$ acid $(\mu \mathrm{g} / \mathrm{dL})$} & Week 0 & $5.7 \pm 0.8$ & $0.02 \pm 0.83$ & $5.4 \pm 1.5$ & $0.37 \pm 1.15$ \\
\hline & Week 8 & $5.6 \pm 1.1$ & & $5.8 \pm 1.6$ & \\
\hline \multirow[t]{2}{*}{ Creatinine $(\mu \mathrm{g} / \mathrm{dL})$} & Week 0 & $1.0 \pm 0.2$ & $-0.01 \pm 0.10$ & $0.9 \pm 0.2$ & $0.02 \pm 0.08$ \\
\hline & Week 8 & $1.0 \pm 0.2$ & & $0.9 \pm 0.2$ & \\
\hline
\end{tabular}

Values are expressed as mean \pm SD.

\# Significantly different between placebo and XOS groups at $p<0.05$ based on Student's $t$ test.

$+\cdot \dot{\sim}$ Significant difference from the baseline in the XOS group at $p<0.05,0.01$, respectively, based on paired-t-test.

XOS, xylooligosaccharides; HbA1c, glycosylated hemoglobin; GOT, glutamate oxaloacetate transaminase; GPT, glutamate pyruvate transaminase.

and stored at $-20^{\circ} \mathrm{C}$ until used. In brief, the serum sample $(200 \mu \mathrm{L})$ and internal standard solution $(50 \mu \mathrm{L})$ were added to a tube with a round-bottomed stopper and put in an ice-cold bath. Then $50 \mu \mathrm{L}$ of $10 \%$ ice-cold sulfosalicylic acid solution was added to the tube and mixed intermittently on a vortex for $30 \mathrm{~s}$. The tube was allowed to stand in the ice-cold bath for 20 min. Three milliliters of diethyl ether were added, mixed, and centrifuged at $15,000 \times g$ for $10 \mathrm{~min}$ at $4^{\circ} \mathrm{C}$. The diethyl ether layer was transferred to another conical stoppered tube containing $50 \mu \mathrm{L}$ of $0.2 \mathrm{M} \mathrm{NaOH}$. After vortex-mixing and centrifugation at $1,500 \times g$ for $30 \mathrm{~s}$, the diethyl ether layer was discarded. One milliliters of fresh diethyl ether was added, followed by vortexmixing and centrifugation at $1,500 \times g$ for $30 \mathrm{~s}$, and then the diethyl ether layer was discarded. This process was repeated once again. The residual organic phase was evaporated under a stream of nitrogen. A $10 \mu \mathrm{L}$ volume of $25 \%$ phosphoric acid was added to the aqueous phase, and then $1 \mu \mathrm{L}$ aliquot of the solution was injected onto the chromatographic system (GC-14A Shimadzu, Japan).

Statistical analysis. All data were expressed as mean \pm standard error of mean (SEM) and analyzed using SPSS 10.0 software (SPSS Inc., Chicago, IL, USA). The differences between the placebo and XOS groups were evaluated by Student's $t$ test, while the difference between the data at the baseline and posttest were evaluated by a paired-t-test. The correlations between the MDA concentration, and SOD, CAT and GSH-Px activi- 
Table 3. Fasting serum lipids and SCFA levels in type 2 DM subjects supplied with placebo or XOS for $8 \mathrm{wk}$.

\begin{tabular}{|c|c|c|c|c|c|}
\hline & & \multicolumn{2}{|c|}{ Placebo } & \multicolumn{2}{|c|}{ XOS } \\
\hline & & $(n=12)$ & Change & $(n=14)$ & Change \\
\hline \multirow[t]{2}{*}{ Triglyceride (mg/dL) } & Week 0 & $110.7 \pm 36.8$ & $13.42 \pm 49.84$ & $134.9 \pm 85.7$ & $-33.46 \pm 68.83$ \\
\hline & Week 8 & $124.1 \pm 63.3$ & & $101.4 \pm 56.2$ & \\
\hline \multirow[t]{2}{*}{ Total cholesterol (mg/dL) } & Week 0 & $196.2 \pm 23.5$ & $9.73 \pm 14.87$ & $194.3 \pm 36.8$ & $-27.00 \pm 43.17^{\#, \dagger}$ \\
\hline & Week 8 & $205.9 \pm 30.1$ & & $167.3 \pm 33.0^{\# \#, \dagger}$ & \\
\hline \multirow[t]{2}{*}{ LDL-cholesterol (mg/dL) } & Week 0 & $121.9 \pm 24.0$ & $6.07 \pm 14.33$ & $106.8 \pm 33.3$ & $-7.08 \pm 24.21$ \\
\hline & Week 8 & $128.0 \pm 26.3$ & & $99.7 \pm 27.0^{\# \#}$ & \\
\hline \multirow[t]{2}{*}{ ox-LDL (U/L) } & Week 0 & $60.3 \pm 14.3$ & $7.20 \pm 20.16$ & $48.5 \pm 14.2$ & $-7.05 \pm 8.54^{\dagger}$ \\
\hline & Week 8 & $64.2 \pm 27.5$ & & $38.0 \pm 9.6^{\#, \dagger}$ & \\
\hline \multirow{2}{*}{ HDL-cholesterol (mg/dL) } & Week 0 & $52.7 \pm 14.0$ & $0.58 \pm 6.08$ & $51.0 \pm 10.8$ & $-2.62 \pm 6.74$ \\
\hline & Week 8 & $110.7 \pm 10.4$ & & $47.6 \pm 10.4$ & \\
\hline \multirow[t]{2}{*}{ Apolipoprotein A-I (mg/dL) } & Week 0 & $138.5 \pm 24.5$ & $-3.31 \pm 31.17$ & $134.6 \pm 18.1$ & $-0.83 \pm 14.92$ \\
\hline & Week 8 & $135.2 \pm 28.7$ & & $131.1 \pm 23.4$ & \\
\hline \multirow[t]{2}{*}{ Apolipoprotein B (mg/dL) } & Week 0 & $90.0 \pm 17.7$ & $4.75 \pm 13.32$ & $90.9 \pm 26.5$ & $-15.49 \pm 15.86^{\# \ddagger}$ \\
\hline & Week 8 & $94.7 \pm 26.5$ & & $75.4 \pm 19.5^{\#, \$}$ & \\
\hline \multirow[t]{2}{*}{ Acetate $(\mathrm{mmol} / \mathrm{L})$} & Week 0 & $0.11 \pm 0.05$ & $-0.008 \pm 0.006$ & $0.10 \pm 0.02$ & $-0.002 \pm 0.058$ \\
\hline & Week 8 & $0.11 \pm 0.04$ & & $0.09 \pm 0.05$ & \\
\hline \multirow[t]{2}{*}{ Propionate (mmol/L) } & Week 0 & $0.09 \pm 0.01$ & $-0.002 \pm 0.018$ & $0.10 \pm 0.01$ & $0.033 \pm 0.134$ \\
\hline & Week 8 & $0.10 \pm 0.01$ & & $0.10 \pm 0.02$ & \\
\hline \multirow[t]{2}{*}{ Butyrate (mmol/L) } & Week 0 & $0.07 \pm 0.05$ & $-0.018 \pm 0.031$ & $0.06 \pm 0.03$ & $-0.015 \pm 0.041$ \\
\hline & Week 8 & $0.05 \pm 0.05$ & & $0.05 \pm 0.03$ & \\
\hline
\end{tabular}

Values are expressed as mean \pm SD.

\#,\#\# Significantly different between placebo and XOS groups at $p<0.05,0.01$, respectively, based on Student's $t$ test.

$t+$ Significant difference from the baseline in the XOS group at $p<0.05,0.01$, respectively, based on paired-t-test.

XOS, xylooligosaccharides; LDL-cholesterol=Total cholesterol-HDL-cholesterol-Triglyceride/ 5 .

Table 4. Oxidative status in type 2 DM subjects supplied with placebo or XOS for 8 wk.

\begin{tabular}{|c|c|c|c|c|c|}
\hline & & \multicolumn{2}{|c|}{ Placebo } & \multicolumn{2}{|c|}{ XOS } \\
\hline & & $(n=12)$ & Change & $(n=14)$ & Change \\
\hline \multirow[t]{2}{*}{ TBARS (nmol/mL) } & Week 0 & $3.98 \pm 0.35$ & $-0.27 \pm 0.48$ & $3.71 \pm 0.88$ & $0.29 \pm 0.80^{\#}$ \\
\hline & Week 8 & $3.71 \pm 0.60$ & & $4.04 \pm 1.09$ & \\
\hline \multirow[t]{2}{*}{ Catalase (U/g protein) ${ }^{\mathrm{a}}$} & Week 0 & $0.24 \pm 0.05$ & $-0.03 \pm 0.05$ & $0.22 \pm 0.06$ & $-0.05 \pm 0.05$ \\
\hline & Week 8 & $0.20 \pm 0.05$ & & $0.17 \pm 0.05$ & \\
\hline \multirow{2}{*}{$\mathrm{SOD}(\mathrm{U} / \mathrm{g} \text { protein })^{\mathrm{b}}$} & Week 0 & $0.20 \pm 0.16$ & $0.06 \pm 0.17$ & $0.23 \pm 0.20$ & $0.09 \pm 0.22$ \\
\hline & Week 8 & $0.26 \pm 0.11$ & & $0.32 \pm 0.29$ & \\
\hline \multirow[t]{2}{*}{ GSH-Px (U/g protein $)^{c}$} & Week 0 & $9.20 \pm 4.32$ & $1.75 \pm 8.05$ & $8.90 \pm 5.75$ & $1.76 \pm 6.60$ \\
\hline & Week 8 & $11.48 \pm 6.85$ & & $10.66 \pm 6.87$ & \\
\hline
\end{tabular}

Values are expressed as mean \pm SD.

${ }^{\text {a }}$ Catalase $(\mathrm{U} / \mathrm{g}$ protein $)=$ Catalase $\left(\mathrm{mol} \mathrm{H} \mathrm{H}_{2} / \mathrm{min} / \mathrm{g}\right.$ protein $)$.

${ }^{\mathrm{b}} \mathrm{SOD}(\mathrm{U} / \mathrm{g}$ protein $)=$ SOD (reduce pyrogallol $1 / 2$ autoxidative/g protein).

${ }^{\mathrm{c}} \mathrm{GSH}-\mathrm{Px}=(\mathrm{mol} \mathrm{NADPH} / \mathrm{min} / \mathrm{g}$ protein $)$.

\# Significantly different between placebo and XOS groups at $p<0.05$ based on Student's $t$ test.

${ }^{\ddagger}$ Significant difference from the baseline in the XOS group at $p<0.01$ based on paired-t-test.

ties were assessed by Pearson's correlation method. Differences were considered to be significant at 0.05 levels.

\section{RESULTS}

Characteristics and nutrient parameters of the subjects

The characteristics of tested subjects and the anthropometric, hematological and biochemical values of the subjects are provided in Tables 1 and 2 . The mean age and duration of DM did not differ between the placebo and XOS groups, while the glucose, HbA1c and fructosamine concentrations of the subjects significantly reduced after XOS supplementation for a period of $8 \mathrm{wk}$. However, the XOS supplementation did not change the body weight, BMI, body fat, insulin, GOT, GPT, BUN or creatinine values.

The serum lipids and SCFA values of the subjects are shown in Table 3. After $8 \mathrm{wk}$ XOS supplementation, the total cholesterol, LDL-cholesterol, ox-LDL and apolipo- 
protein B values decreased significantly. However, XOS supplement did not affect the fasting serum short-chain fatty acids in type 2 DM subjects. The above results revealed that the XOS supplemented at the concentration of $4 \mathrm{~g} / \mathrm{d}$ for $8 \mathrm{wk}$ could lower the blood sugar and lipid levels of type 2 DM subjects.

Antioxidant status of the subjects

The antioxidant status of the subjects is shown in Table 4. The results revealed that the XOS supplementation did not influence the level of TBARS or the activities of superoxide dismutase and glutathione peroxidase but it did significantly reduce the activity of catalase. Meanwhile, the change of TBARS level in XOS group was significantly different from that of the placebo group. However, we did not find significant correlations between the MDA concentration and SOD, CAT and GSH-Px activities.

Gastrointestinal function and nutrient intakes of the subjects

According to the subjects' report, their lifestyles remained constant throughout this study. The treatment of diabetes was maintained for each patient throughout the study; furthermore, no gastrointestinal complaint was reported. Compliance, expressed as the proportion of powder paper bag not returned, was near $100 \%$ during the experimental period. The daily calories and nutrient intakes also did not change throughout the study in either the placebo or XOS group (data not shown).

\section{DISCUSSION}

Our results showed that the XOS supplementation for 8 wk could reduce the blood glucose, HbA1c, and fructosamine and also decrease total cholesterol, LDL-cholesterol, ox-LDL and apolipoprotein B in type 2 DM patients. However, the body weight and daily nutrient intakes of the subjects remained stable during the supplementation of XOS for $8 \mathrm{wk}$. Thus, we deduced that the lower glycemia and lipidemia after the XOS treatment was due to the effect of the treatment itself, not a change in body weight or diet.

The effects of oligosaccharides including FOS and XOS on blood glucose and lipid concentrations were complicated. For example, Yamashita et al. (7) demonstrated that FOS administration at a dose of $8 \mathrm{~g} / \mathrm{d}$ for 14 $\mathrm{d}$ resulted in a decrease of fasting blood glucose in type 2 DM patients. Vanhoof and de Schrijver (17) showed that inulin reduced cholesterol in normocholesterolemic rats presumably by increasing the excretions of fecal neutral steroids and bile acids, whereas it had no effect on the plasma cholesterol concentration in hypercholesterolemic rats. It has also been shown that daily ingestion of 6-12 g oligosaccharides for 2-3 mo could reduce total serum cholesterol in humans by $0.226-$ $0.566 \mathrm{mmol} / \mathrm{L}(18)$. In contrast, the daily consumption of FOS was stated to have no effects on blood glucose, serum lipids or serum acetate in individuals with type 2 DM (8) nor did it affect the fasting plasma glucose in individuals with mild hypercholesterolaemia (19). Chung et al. (20) found that $4 \mathrm{~g} / \mathrm{d}$ XOS supplementa- tion for 8 wk showed no influence on the fasting sugar, triglyceride or cholesterol levels in normal glycemia elderly subjects. Gostner et al. (21) reported that isomalt supplementation did not influence the fructosamine or oxidized LDL levels in healthy volunteers. The above studies indicated that oligosaccharide appeared to have no significant effect on the levels of blood sugar or lipid in healthy, hypercholesterolaemia and non-diabetic patients. However, the concept of blood glucose and lipid assimilations by oligosaccharide in type $2 \mathrm{DM}$ subjects is divergent. The types of oligosaccharides as well as the duration of the treatment may influence the results.

XOS supplementation has been demonstrated to significantly increase the Bifidobacteria population and SCFA in the intestinal tract $(4,5,20)$. Hidaka (22) suggested that one mechanism for oligosaccharide on reducing the serum cholesterol level was considered to be the alteration of the intestinal microflora. Furthermore, the decline of cholesterol level might be because oligosaccharides could decrease the expressions of the enzymes for fatty acid synthesis (23), reduce the cholesterol absorption efficiency and increase the faecal bile acid and cholesterol excretions (24). On the other hand, SCFAs, such as propionate, have also been proposed to influence glucose and lipid metabolisms $(5,19)$. Laurent et al. (6) reported that infusing SCFA to healthy subjects decreased serum free fatty acid concentrations. Venter et al. (5) demonstrated that a propionate supplement decreased fasting serum glucose, and improved glucose tolerance and insulin sensitivity. However, we did not find a significant effect of XOS on the fasting serum SCFA levels in type 2 DM patients. The mechanism of XOS to influence glucose and lipid metabolism need further study.

Higher lipid peroxidation in the blood is one of the important symptoms in DM patients. Diabetic patients showed higher serum and erythrocyte lipid peroxidations (25). Thus, reduced lipid peroxidation and improved antioxidant status might be one mechanism by which dietary treatment contributes to the prevention of diabetic complications. Sekeroglu et al. (25) reported that the serum and erythrocyte lipid peroxidation of diabetic patients significantly decreased after dietary treatment, whereas our results did not show any beneficial effect of XOS supplementation on the TBARS level. Moreover, they also reported that the glucose level of DM subjects was decreased by $23.2 \%$, while we found the glucose level decreased only $7.8 \%$ which was lower than their results. Thus, the effect of dietary treatment on the TBARS level in DM patients might be affected by the differential result on lowering the glucose level. Moreover, in diabetic patients with microvascular complications or coronary heart disease, the CAT activity was increased, GPx activity was decreased and no change was observed in SOD activity when compared to controls $(26,27)$. Aydin et al. $(28)$ found that oral antidiabetic treatment decreased the erythrocyte SE-GPx and CAT activities below the control values. Our results showed that the activity of CAT in type 2 
DM patients decreased significantly after XOS supplementation. We further analyzed the relation between the value of TBARS and antioxidant enzyme. However, no significant correlation was found among these parameters.

In conclusion, our results demonstrated that XOS supplementation at $4 \mathrm{~g} / \mathrm{d}$ for $8 \mathrm{wk}$ improved the blood sugar and serum lipids levels in patients with type 2 DM, indicating that XOS containing diets might be beneficial to DM subjects. The mechanisms of XOS to affect the blood sugar and serum lipid are of interest and worth further study.

\section{Acknowledgments}

This work was supported by grants from the Taichung Veterans General Hospital and Providence University (TCVGH-PU 948101 and TCVGH-PU 958106) Taichung, Taiwan, Republic of China.

\section{REFERENCES}

1) Okazaki M, Koda H, Izumi R, Fujikawa S, Matsumoto N. 1991. In vitro digestibility and in vivo utilization of xylobiose. Nippon Eiyo Shokuryo Gakkaishi 44: 41-44.

2) Chung YC, Hsieh CP, Chan YC. 2002. Effects of xylooligosaccharides on the intestinal properties of ICR mice. Taiwanese J Agric Chem Food Sci 40: 377-384.

3) Hsu CK, Liao JW, Chung YC, Hsieh CP, Chan YC. 2004. Xylooligosaccharides and fructooligosaccharides affect the intestinal microbiota and precancerous colonic lesion development in rats. J Nutr 134: 1523-1528.

4) Campbell JM, Fahey GC Jr, Wolf BW. 1997. Selected indigestible oligosaccharides affect large bowel mass, cecal and fecal short-chain fatty acids, $\mathrm{pH}$ and microflora in rats. J Nutr 127: 130-136.

5) Venter CS, Vorster HH, Cummings JH. 1990. Effects of dietary propionate on carbohydrate and lipid metabolism in healthy volunteers. Am J Gastroenterol 85: 549553.

6) Laurent C, Simoneau C, Marks L, Braschi S, Champ M, Charbonnel B, Krempf M. 1995. Effect of acetate and propionate on fasting hepatic glucose production in humans. Eur J Clin Nutr 49: 484-491.

7) Yamashita K, Kawai K, Itakura M. 1984. Effects of fructo-oligosaccharides on blood glucose and serum lipids in diabetic subjects. Nutr Res 4: 961-966.

8) Alles MS, de Roos NM, Bakx JC, van de Lisdonk E, Zock PL, Hautvast GA. 1999. Consumption of fructooligosaccharides does not favorably affect blood glucose and serum lipid concentrations in patients with type 2 diabetes. Am J Clin Nutr 69: 64-69.

9) Department of Health, Taiwan. 1999. Health Food Management Regulations. [Online], Available: http://www. doh.gov.tw [accessed March 23, 2007].

10) van Munster IP, de Boer HM, Jansen MC, de Haan AF, Katan MB, van Amelsvoort JM, Nagengast FM. 1994. Effect of resistant starch on breath-hydrogen and methane excretion in healthy volunteers. Am J Clin Nutr 59: 626-630.

11) Friedewald WT, Levy RI, Fredrickson DS. 1972. Estimation of the concentration of low-density lipoprotein cholesterol in plasma without use of the preparative ultracentrifuge. Clin Chem 18: 499-502.

12) Ohkawa H, Ohishi N, Yagi K. 1979. Assay for lipid per- oxides in animal tissues by thiobarbituric acid reaction. Anal Biochem 95: 351-358.

13) Marklund S, Marklund G. 1974. Involvement of the superoxide anion radical in the autoxidation of pyrogallol and a convenient assay for superoxide dismutase. Eur J Biochem 47: 469-474.

14) Aebi H. 1983. Catalase. In: Methods of Enzymatic Analysis (Bergmeyer HU, ed), p 673-686. VCH, Weinhein Deerfield Beach, FL.

15) Paglia DE, Valentine WN. 1967. Studies on the qualitative characterization of erythrocyte glutathione peroxidase. J Lab Clin Med 70: 159-169.

16) Murase M, Kimura Y, Nagata Y. 1995. Determination of portal short-chain fatty acids in rats fed various dietary fibers by capillary gas chromatography. J Chromatogr B Biomed Appl 664: 415-420.

17) Vanhoof K, de Schrijver RL. 1995. Effect of unprocessed and baked inulin on lipid metabolism in normo- and hypercholesterolemic rats. Nutr Res 15: 1637-1646.

18) Hata Y, Hara T, Oikawa T, Yamamoto M, Hirose N, Nagashima T, Torihama N, Nakajima K, Watabe A, Yamashita M. 1983. The effects of fructosaccharides against hyperlipidemia. Clin Geriatr Med 21: 156-167.

19) Giacco R, Clemente G, Luongo D, Lasorella G, Fiume I, Brouns F, Bornet F, Patti L, Cipriano P, Rivellese AA, Riccardi G. 2004. Effects of short-chain fructo-oligosaccharides on glucose and lipid metabolism in mild hypercholesterolaemic individuals. Clin Nutr 23: 331-340.

20) Chung YC, Hsu CK, Ko CY, Chan YC. 2007. Dietary intake of xylooligosaccharides improve the intestinal microbiota, fecal moisture and $\mathrm{pH}$ value in the elderly. Nutr Res 27: 756-761.

21) Gostner A, Schaffer V, Theis S, Menzel T, Luhrs H, Melcher R, Schauber J, Kudlich T, Dusel G, Dorbath D, Kozianowski G, Scheppach W. 2005. Effects of isomalt consumption on gastrointestinal and metabolic parameters in healthy volunteers. Br J Nutr 94: 575-581.

22) Hidaka H. 1985. The role of intestinal flora in nutrition. Biseibutsu (Microbe) 1: 32-40.

23) Williams CM. 1999. Effects of inulin on lipid parameters in humans. J Nutr 129: 1471S-1473S.

24) van Bennekum AM, Nguyen DV, Schulthess G, Hauser H, Phillips MC. 2005. Mechanisms of cholesterol-lowering effects of dietary insoluble fibres: relationships with intestinal and hepatic cholesterol parameters. Br J Nutr 94: 331-337.

25) Sekeroglu MR, Sahin H, Dulger H, Algun E. 2000. The effect of dietary treatment on erythrocyte lipid peroxidation, superoxide dismutase, glutathione peroxidase, and serum lipid peroxidation in patients with type 2 diabetes mellitus. Clin Biochem 33: 669-674.

26) Kesavulu MM, Giri R, Kameswara Rao B, Apparao C. 2000. Lipid peroxidation and antioxidant enzyme levels in type 2 diabetics with microvascular complications. Diabetes Metab 26: 387-392.

27) Kesavulu MM, Rao BK, Giri R, Vijaya J, Subramanyam G, Apparao C. 2001. Lipid peroxidation and antioxidant enzyme status in type 2 diabetics with coronary heart disease. Diabetes Res Clin Pract 53: 33-39.

28) Aydin A, Orhan H, Sayal A, Ozata M, Sahin G, Isimer A. 2001. Oxidative stress and nitric oxide related parameters in type 2 diabetes mellitus: effects of glycemic control. Clin Biochem 34: 65-70. 